\title{
Association of mammography with sociodemographic and care factors in residents of Belo Horizonte, MG, Brazil
}

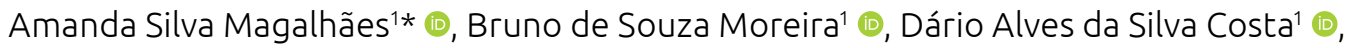 \\ Amanda Cristina de Souza Andrade² (1), Waleska Teixeira Caiaffa' (1)
}

\section{ABSTRACT}

Objective: This study aimed to investigate screening mammography in the last two years, sociodemographic factors, and healthcare service use among women aged 40-69 years living in a Brazilian urban center. Methods: The data are part of a household survey called "MOVE-SE Academias" (2014/2015) carried out in Belo Horizonte (MG). The sample was selected using a stratified threestage cluster sampling: Health Academy Program units distributed in the city, census tracts, and households. Pearson's chi-square test was used in the analysis. Results: Of the 371 women included in this study with a mean age of 52.5 years, $66.2 \%$ among those aged $40-49$ years $(n=157)$ and $75.7 \%$ among those aged $50-69$ years $(n=214)$ reported being submitted to mammography within two years before the interview. When it comes to women aged 40-49 and 50-69 years, a higher proportion was found among those with higher schooling ( $p=0.011$ and $p=0.001)$, who had been to medical appointments in less than one year $(p=0.024$ and $p<0.001)$, who had performed the Pap smear test in less than two years $(p<0.001$ for both groups) and who reported having a private health insurance ( $p=0.007$ and $p=0.008$ ). Higher family income was associated only with the performance of the screening exam among women aged $40-49$ years $(p=0.006)$. Conclusion: Our results suggest inequalities in access to health services for breast cancer screening, modulated by socioeconomic factors, including private health insurance. Prioritizing more vulnerable groups in cancer screening as a public policy can contribute to reducing health inequalities.

KEYWORDS: mammography; radiology; women's health; health services; health status disparities; urban health.

\section{INTRODUCTION}

Worldwide, breast cancer is more common among women and the leading cause of specific mortality in this group ${ }^{1}$. The estimates for 2020 are 1.97 million new cases of breast cancer and 622 thousand deaths from the disease worldwide ${ }^{2}$. In Brazil, the National Cancer Institute "José Alencar Gomes da Silva" estimated 66,280 new cases of breast cancer each year in the 20202022 triennium, corresponding to an estimated risk of 61.61 new cases per 100,000 women ${ }^{3}$. In 2017, approximately 17,000 deaths of women from breast cancer in the country were accounted for by the national mortality statistics available ${ }^{4}$. Expressive mortality from the disease is associated with high incidence and late diagnosis. Thus, early detection, a form of secondary prevention, is essential for reducing mortality, as it aims to identify cancer in early stages when prognosis is better 5 .
There are two strategies for the early detection of breast cancer: early diagnosis and screening ${ }^{6,7}$. Early diagnosis seeks to identify people with initial signs and/or symptoms of the disease, striving for quality, and ensuring comprehensive care in all stages of the care line ${ }^{5}$. This can contribute to reducing progression to subsequent stages ${ }^{8}$, in addition to increasing the chances of cure and enabling the use of less aggressive and systemic therapeutic forms, leading to a faster recovery and minimal sequelae ${ }^{9}$. The most accepted strategy for early diagnosis of breast cancer today is made up of a triad: population alert to suspicious signs and symptoms of cancer, health professionals trained to evaluate suspected cases, and health services prepared to ensure timely diagnostic confirmation and with quality ${ }^{7}$.

In turn, screening involves a systematic application of simple and easily performed tests on supposedly asymptomatic individuals (in the preclinical phase) to identify abnormalities

${ }^{1}$ Universidade Federal de Minas Gerais - Belo Horizonte (MG), Brazil. 2Universidade Federal de Mato Grosso - Cuiabá (MT), Brazil.

*Corresponding author: amandasmagalhaes@hotmail.com

Conflict of interest: nothing to declare.

Received on: 03/09/2020. Accepted on: 05/13/2020. 
suggestive of the disease ${ }^{6}$. The Ministry of Health recommends mammography for breast cancer screening ${ }^{7}$ because it is a fast, non-invasive, and low-cost exam in comparison to other imaging exams. In addition, it is associated with acceptable side effects, brings reproducible results, and can be applied to the population at regular intervals and reasonable costs to societ $y^{10}$. These advantages make mammography the method of choice for screening breast cancer on a large scale and at population levels.

The World Health Organization (WHO) recommends mammographic screening every two years for women over the age of 50 , so as to cover more than $70 \%$ of this population ${ }^{11}$. In Brazil, the Ministry of Health recommends screening for breast cancer by mammography every two years for women aged between 50 and 69 years ${ }^{7}$, while the Brazilian Society of Mastology (SBM), the Brazilian College of Radiology and Diagnostic Imaging (CBR) and the Brazilian Federation of Gynecology and Obstetrics Associations (Febrasgo) suggest that it should be performed annually for women aged 40 years or older ${ }^{12}$. The criticism of these Brazilian medical societies about biennial screening in patients aged 50 years or older stems from tumors, in some women, tending to develop at an earlier age; therefore, screening at an older age and longer intervals between exams could result in diagnosis in more advanced stages ${ }^{12}$. In turn, the criticism of the recommendation that includes younger women and the short interval between exams concerns the negative balance between possible benefits and risks, such as greater exposure to ionizing radiation and problems associated with overdiagnosis and overtreatment ${ }^{13}$.

Despite advances in the field of women's health in the country, access to mammography still is not equal among Brazilian women, being marked by socioeconomic, racial, educational, and regional inequalities. Previous studies have reported that a higher level of education and income, white skin color, and living in an urban area or more developed regions of the country are associated with better adherence to mammography ${ }^{14-17}$. In addition, it was previously observed that women who consulted a physician in the last year and those who reported having private health insurance are more likely to undergo the exam ${ }^{15-17}$. Therefore, identifying the characteristics related to the mammography exam is extremely important to guide public health policies, so as to reduce inequalities in this area.

In view of the above, this study was conducted with the following objectives:

- to estimate the proportion of mammography exams performed in the last two years before the interview by women aged 40-49 and 50-69 years, living in a Brazilian urban center;

- to investigate the sociodemographic and health service use factors associated with mammography by age group.

\section{METHODS}

\section{Study design and ethical aspects}

This is a cross-sectional study based on information from a population-based household survey called Lifestyles and Health Project - Study on Health Academies and Similar in Brazilian Municipalities: from Understanding the Program to Effectiveness of Actions (MOVE-SE Academias), conducted by researchers from the Urban Health Observatory of Belo Horizonte, Universidade Federal de Minas Gerais.

"MOVE-SE Academias" was carried out in the nine health districts of Belo Horizonte (Minas Gerais) and aimed to evaluate the residents of the geographic surroundings of the Health Academy Program (PAS, acronym in Portuguese), including its users and non-users.

PAS was implemented in Belo Horizonte in 2006, preferably in areas of social vulnerability. This program operates in owned or shared public places and offers free physical activity classes supervised by physical educators, in addition to health promotion initiatives such as nutritional guidance and other community education activities for people over 18 years referred by the Basic Health Units (BHU) and also by spontaneous demand ${ }^{18,19}$.

Data were collected from the "MOVE-SE Academias" Project between November 2014 and March 2015, in face-to-face interviews using a standardized questionnaire that assessed topics related to the individual, home-related and neighborhood characteristics, as well as aspects related to participation in the PAS and health service use. More details about the "MOVE-SE Academias" can be obtained in a previous publication ${ }^{20}$.

The study was approved by the Research Ethics Committee of Universidade Federal de Minas Gerais under protocol no. 26152814.2.0000.5149, and all volunteers signed an informed consent form to participate in the study.

\section{Study sample}

Sample selection of PAS non-users had a probabilistic design by clusters and was made in three stages: PAS poles, census sectors, and households.

Of the 63 poles of the program in the city of Belo Horizonte in 2014 that were included in the list of the Municipal Health Department, those with implementation until the first semester of 2013 and not directed to special groups (older adults and institutional workers) or located in specific points (universities, condominiums, and district markets) were considered eligible. Of the 44 eligible poles, 10 were randomly selected, three of which were inherited from a previous study ${ }^{20}$, with respective probability 1 of the census tracts where they were located.

The remaining census tracts were sampled around the poles with different probabilities and sample size proportional to the total number of tracts in the surroundings. Census tracts located up to $500 \mathrm{~m}$ from any pole were 2.4 times more likely to be drawn 
compared to those located more than $500 \mathrm{~m}$ away. The households were selected using systematic sampling based on the number of households per census tract according to data from the 2010 census. In each household, an adult resident (18 years or older) was elected according to the quota established by sex and age group. With this strategy, the final sample of the study consisted of 1,376 respondents: 544 men and 832 women.

For the present study, we analyzed information of 378 women aged 40 to 69 years who were not PAS users and lived in the surroundings of where the program was conducted.

\section{Study variables}

The dependent variable was the performance of mammography by women aged 40 years or older evaluated by the question "When was the last time you had a mammography exam?". Answer options were: "less than a year", "one year to less than two years", "two years to less than three years", "three years or more" and "never done it". The responses were categorized as "performed" or "did not perform" mammography within the time frame of two years before the interview.

The independent variables were selected based on the literature ${ }^{8,15,16}$ and grouped into two blocks: sociodemographic characteristics and health service use. The variables in the first block included: skin color (white and non-white), marital status (without a partner and with a partner), complete years of schooling (0-4, 5-8, 9-11, and $\geq 12$ years), paid work (yes and no) and family income $(<1,1-2$, and $\geq 3$ minimum wages). The variables in the second block were: medical appointments, evaluated by the question "When was the last time that you consulted a physician?" (less than a year and more than a year); Pap smear test, evaluated by the question "When was the last time you had a preventive exam for cervical cancer?" (less than two years, two years or more, and never done it); use of BHU, measured by the question "In the last 12 months, how often did you go to a BHU (for appointments, physical therapy, prevention, vaccination, obtaining medicines, etc.)?" (often, occasionally, rarely, and never); and possession of a private health insurance (yes and no).

\section{Data analysis}

A descriptive analysis of sociodemographic characteristics and variables related to health service use was carried out using absolute and relative frequency distribution (\%) and applying the Pearson's $\chi^{2}$ test to identify the variables associated with the mammography exam. All analyses were performed using the STATA statistical package, version 12.0 (StataCorp LP, College Station, United States). A 5\% confidence level was adopted.

\section{RESULTS}

Among 832 women interviewed, 378 were between 40 and 69 years and, therefore, were eligible for this study. Seven participants were excluded due to the lack of information on the mammography exam, totaling 371 participants: 157 in the $40-49$ age group and 214 in the 50-69 age group (Figure 1).

Table 1 lists the characteristics of the sample and shows the comparison between the percentages of the selected variables between participants who had and had not undergone mammography less than two years before the interview for the age groups 40-49 and 50-69 years. In both groups, most participants were non-white, had a partner, had had a medical appointment less than a year and Pap smear test less than two years before the interview, used BHU frequently, and did not have a private health insurance. In addition, in the 40-49 age group, most women had 9 to 11 years of schooling, had a paid work, and family income was below one minimum wage. In the 50-69 age group, most subjects had zero to four years of schooling, did not have a paid work, and family income was greater than or equal to three minimum wages.

A total of 104 (66.2\%; 95\%CI 58.4-73.2) and 162 (75.7\%; 95\%CI 69.5-81) participants had undergone mammography exam less than two years before the interview among women aged 40-49

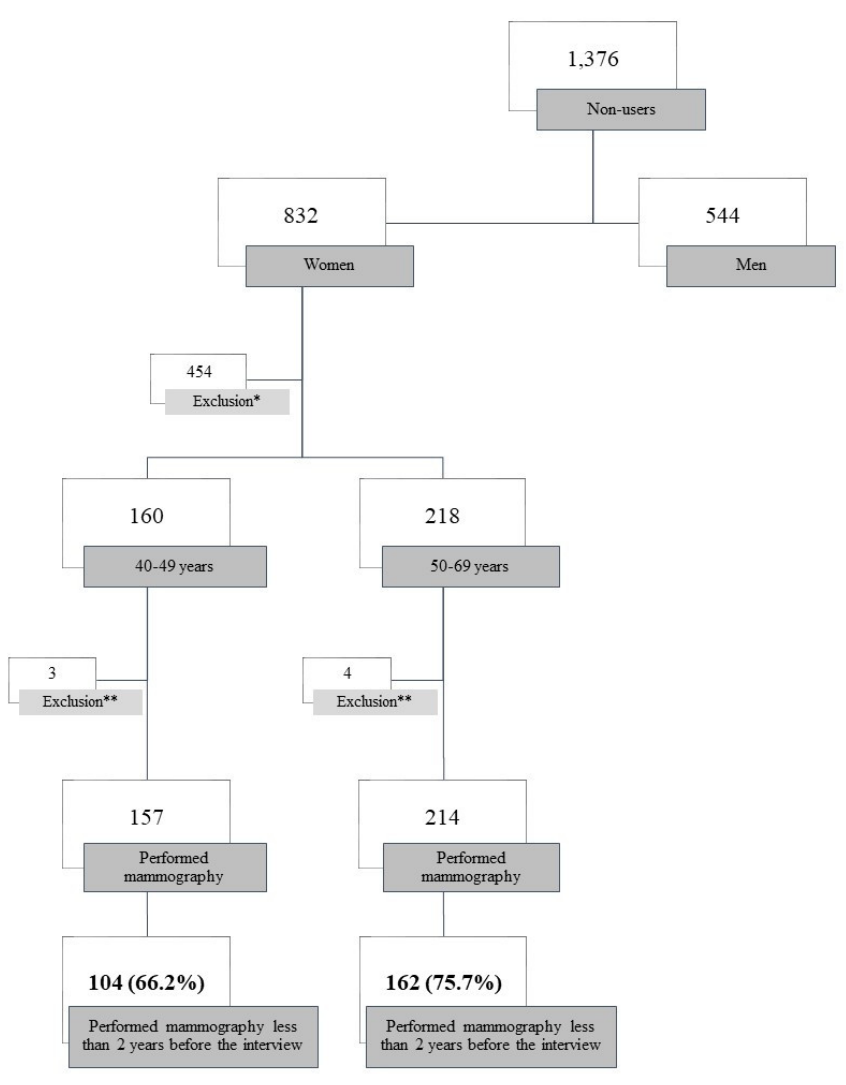

*Other age groups; **one missing datum related to mammography exam. Figure 1. Flowchart showing the proportion of women who had undergone mammography less than two years before the interview for each age group. Belo Horizonte, Minas Gerais, Brazil, 2014-2015. 
and 50-69 years, respectively. In both age groups, the variables significantly associated with the performance of mammography were: higher schooling level, medical appointment less than a year, the performance of Pap smear test less than two years, and having private health insurance. Higher family income was also associated with having the exam among women aged 40-49 years.

As for the health service use among women who had undergone mammography exam less than two years before the interview,

Table 1. Mammography exam performed less than two years before the interview, sociodemographic characteristics, and health service use among women aged 40-49 and 50-69 years. Belo Horizonte, Minas Gerais, Brazil, 2014-2015.

\begin{tabular}{|c|c|c|c|c|c|c|c|c|}
\hline \multirow{3}{*}{ Characteristics } & \multicolumn{4}{|c|}{$40-49$ years } & \multicolumn{4}{|c|}{$50-69$ years } \\
\hline & \multirow{2}{*}{$\begin{array}{c}\text { Total } \\
(\mathrm{n}=157) \\
\mathrm{n}(\%)\end{array}$} & \multicolumn{3}{|c|}{$\begin{array}{l}\text { Mammography performed less than } \\
\text { two years before the interview }\end{array}$} & \multirow{2}{*}{$\begin{array}{c}\text { Total } \\
(n=214) \\
n(\%)\end{array}$} & \multicolumn{3}{|c|}{$\begin{array}{l}\text { Mammography performed less than } \\
\text { two years before the interview }\end{array}$} \\
\hline & & $\begin{array}{c}\text { Yes } \\
(n=104) \\
n(\%)\end{array}$ & $\begin{array}{c}\text { No } \\
(n=53) \\
n(\%)\end{array}$ & p-value & & $\begin{array}{c}\text { Yes } \\
(n=162) \\
n(\%)\end{array}$ & $\begin{array}{c}\text { No } \\
(n=52) \\
n(\%)\end{array}$ & p-value \\
\hline
\end{tabular}

Sociodemographic

Skin color*

\begin{tabular}{|c|c|c|c|c|c|c|c|c|}
\hline White & $54(34.4)$ & $41(39.4)$ & $13(24.5)$ & \multirow{2}{*}{0.063} & $70(32.9)$ & $56(34.8)$ & $14(26.9)$ & \multirow{2}{*}{0.294} \\
\hline Non-white & $103(65.6)$ & $63(60.6)$ & $40(75.5)$ & & $143(67.1)$ & $105(65.2)$ & $38(73.1)$ & \\
\hline \multicolumn{9}{|l|}{ Marital status } \\
\hline Without a partner & $51(32.5)$ & $31(29.8)$ & $20(37.7)$ & \multirow{2}{*}{0.316} & $101(47.2)$ & $72(44.4)$ & $29(55.8)$ & \multirow{2}{*}{0.155} \\
\hline With a partner & $106(67.5)$ & $73(70.2)$ & $33(62.3)$ & & $113(52.8)$ & $90(55.6)$ & $23(44.2)$ & \\
\hline \multicolumn{9}{|l|}{ Complete schooling (years) } \\
\hline $0-4$ & $33(21.0)$ & $15(14.4)$ & $18(34.0)$ & \multirow{4}{*}{0.011} & $81(37.8)$ & $52(32.1)$ & $29(55.8)$ & \multirow{4}{*}{0.001} \\
\hline $5-8$ & $44(28.0)$ & $32(30.8)$ & $12(22.6)$ & & $65(30.4)$ & $47(29.0)$ & $18(34.6)$ & \\
\hline $9-11$ & $67(42.7)$ & $45(43.3)$ & $22(41.5)$ & & $45(21.0)$ & $42(25.9)$ & $3(5.8)$ & \\
\hline$\geq 12$ & $13(8.3)$ & $12(11.5)$ & $1(1.9)$ & & $23(10.8)$ & $21(13.0)$ & $2(3.8)$ & \\
\hline \multicolumn{9}{|l|}{ Paid work } \\
\hline No & $73(46.5)$ & $48(46.2)$ & 25 (47.2) & \multirow{2}{*}{0.904} & $128(59.8)$ & $98(60.5)$ & 30 (57.7) & \multirow{2}{*}{0.72} \\
\hline Yes & $84(53.5)$ & $56(53.8)$ & $28(52.8)$ & & $86(40.2)$ & $64(39.5)$ & $22(42.3)$ & \\
\hline \multicolumn{9}{|l|}{ Family income $e^{* * * * *}$} \\
\hline$<1$ minimum wage & $62(39.7)$ & $32(31.0)$ & $30(56.6)$ & \multirow{3}{*}{0.006} & $68(32.8)$ & $48(30.8)$ & $20(39.2)$ & \multirow{3}{*}{0.479} \\
\hline 1-2 minimum wages & $50(32.1)$ & $36(35.0)$ & $14(26.4)$ & & $53(25.6)$ & $40(25.6)$ & $13(25.5)$ & \\
\hline$\geq 3$ minimum wages & 44 (28.2) & 35 (34.0) & $9(17.0)$ & & 86 (41.6) & 68 (43.6) & $18(35.3)$ & \\
\hline
\end{tabular}

Health service use

\begin{tabular}{|c|c|c|c|c|c|c|c|c|}
\hline \multicolumn{9}{|l|}{ Medical appointment } \\
\hline Less than one year & $142(90.5)$ & $98(94.2)$ & $44(83.0)$ & \multirow{2}{*}{0.024} & $193(90.6)$ & $154(95.1)$ & $39(76.5)$ & \multirow{2}{*}{$<0.001$} \\
\hline More than one year & $15(9.5)$ & $6(5.8)$ & $9(17.0)$ & & $20(9.4)$ & $8(4.9)$ & $12(23.5)$ & \\
\hline \multicolumn{9}{|l|}{ Pap smear test } \\
\hline Less than two years & $120(76.4)$ & $99(95.2)$ & $21(39.6)$ & \multirow{3}{*}{$<0.001$} & $158(74.2)$ & $147(90.8)$ & $11(21.6)$ & \multirow{3}{*}{$<0.001$} \\
\hline Two years or more & $32(20.4)$ & $3(2.9)$ & $29(54.7)$ & & $47(22.1)$ & $13(8.0)$ & $34(66.7)$ & \\
\hline Never done & $5(3.2)$ & $2(1.9)$ & $3(5.7)$ & & $8(3.7)$ & $2(1.2)$ & $6(11.7)$ & \\
\hline \multicolumn{9}{|l|}{ Use of Basic Health Units } \\
\hline Often & $55(35.0)$ & $39(37.5)$ & $16(30.2)$ & \multirow{4}{*}{0.235} & $89(41.6)$ & $69(42.6)$ & $20(38.5)$ & \multirow{4}{*}{0.453} \\
\hline Occasionally & $40(25.5)$ & $27(26.0)$ & $13(24.5)$ & & $63(29.4)$ & $45(27.8)$ & $18(34.6)$ & \\
\hline Rarely & $33(21.0)$ & $17(16.3)$ & $16(30.2)$ & & $30(14.0)$ & $21(13.0)$ & $9(17.3)$ & \\
\hline Never & $29(18.5)$ & $21(20.2)$ & $8(15.1)$ & & $32(15.0)$ & $27(16.6)$ & $5(9.6)$ & \\
\hline \multicolumn{9}{|l|}{ Private health insurance } \\
\hline No & $112(71.3)$ & $67(64.4)$ & $45(84.9)$ & \multirow{2}{*}{0.007} & $145(67.8)$ & $102(63.0)$ & $43(82.7)$ & \multirow{2}{*}{0.008} \\
\hline Yes & $45(28.7)$ & $37(35.6)$ & 8 (15.1) & & $69(32.2)$ & $60(37.0)$ & 9 (17.3) & \\
\hline
\end{tabular}

*one missing datum for this variable in the 50-69 age group; **one missing datum for this variable in the $40-49$ age group; ***seven missing data for this variable in the 50-69 age group. 
the relationship between the frequency of use of BHU and private health insurance in both age groups was examined. As expected, a high percentage $(>70 \%)$ of participants without a private health insurance was found among subjects who reported using a BHU frequently in the last 12 months, in both age groups. There was also a high percentage $(>75 \%)$ of participants who had private health insurance among those who reported never having searched a BHU in the last 12 months, in both age groups. Specifically, in the 40-49 age group, it was observed that, among participants who frequently used BHU, 71.8\% did not have a private health insurance, while among those who never searched a BHU, $76.2 \%$ had a private health insurance (Figure 2A). Likewise, in the 50-69 age group, it was found that, among interviewees who frequently used BHU, 79.7\% reported not having a private health insurance and, among those who never searched a BHU, 77.8\% reported having a private health coverage (Figure 2B).

\section{DISCUSSION}

In the age ranges $40-49$ and $50-69$ years, $33 \%$ and $24 \%$ of women living in a Brazilian urban center, respectively, did not perform mammography in the last two years. Higher education, medical appointment, Pap smear test, and having a private health insurance were associated with a higher proportion of taking the exam in both age groups, while family income was only

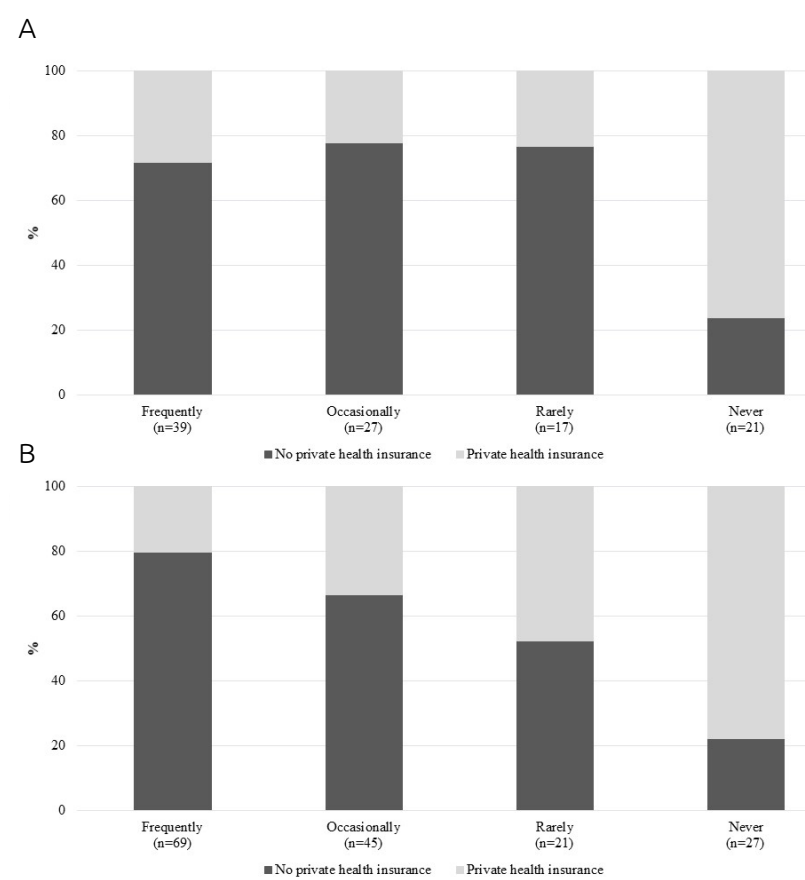

Figure 2. Percentage of private health insurance according to the use of Basic Health Units among women aged (A) 40-49 and (B) 50-69 years who underwent mammography less than two years before the interview. Belo Horizonte, Minas Gerais, Brazil, 2014-2015. relevant for the group 40-49 years, with all comparisons being significant $(p<0.05)$.

Proportions similar to those of our study were reported regarding mammography in the investigated age groups. In the National Household Sample Survey (PNAD, acronym in Portuguese) conducted in 2008, 67.7\% of women in Brazil reported having undergone a mammography exam in the $40-49$ age group $^{14}$. In 2013 the prevalence of mammography performed in the last two years among women aged 50-69 years in Belo Horizonte was 77.5\%, according to the National Health Survey ${ }^{17,21,22}$. It is important to note that this percentage has remained stable, with no upward tendency, considering that the first survey was conducted in 2008 and the second, in 2013, both prior to our study.

Several studies relate inequalities in access to mammography to socioeconomic factors, such as educational level and income $^{14,16,17,22-24}$. The literature shows that the low education level is one of the main barriers faced in the screening of breast cancer $^{14,16,17,22,23}$. More educated women have better access to health information and resources, which can contribute to the performance of mammography at recommended intervals ${ }^{15}$. Additionally, there was a higher percentage of women with higher income in the group that had performed mammography less than two years before the interview in the 40-49 age group, but not in the 50-69 age group. Previous studies have also observed greater access to mammography related to higher income, which is justified by the possibility of direct payment or even of being covered by a private health insurance ${ }^{14,24}$. The lack of association between income and mammography in women aged 50-69 years may stem from the fact that this is the target age group of the Ministry of Health's public policies for breast cancer screening, which cover all women of this age group, regardless of income.

Another aspect reported was the possibility of surveillance bias, which represents the tendency to look more carefully for an outcome in one of the comparisons groups ${ }^{25}$, as well as the finding that the medical appointments were associated with mammography exam less than two years before the interview in both age groups. Previous studies indicate that this variable can be an important predictor for the performance of mammography, but it can also be considered one of the first barriers faced for the examination ${ }^{14-17}$, as the lack of periodic medical appointments may indicate difficulty in accessing the health service and/or lack of self-health care in general ${ }^{26}$. Women who had not seen a physician less than a year before study have one-third of the chance of undergoing mammography when compared to women who had seen a physician less than a year before survey ${ }^{14,15}$. Therefore, expanding access to medical appointments can positively impact early detection of breast cancer. In the same direction, we found that the Pap smear test, an indicator of gynecological consultation, was significantly associated with the performance of mammography in both age groups, suggesting that the actions to prevent cervical and breast cancer, coordinated 
by basic care and usually treated together, as part of preventive health care ${ }^{16,26}$, represent a line of comprehensive care for women.

As for coverage by a private health insurance, the significantly higher percentage of women who reported having a health insurance in the group that had undergone mammography less than two years before the interview compared to the group that did not, in both age groups, takes us to the discussion of the role of the private health insurance. Some studies have shown that individuals with private health coverage use health services more frequently when compared to those who use only the public health system $^{16,17,27}$. In addition, having health insurance coverage is an important factor for better access to mammography reported in the literature ${ }^{26}$. Thus, it is plausible to infer that having a private health insurance may have contributed to the performance of mammography among the participants of our study, since health insurance users use health services more frequently, have more contact with health professionals, and are more commonly referred to exams, in addition to higher availability of mammography devices in the private sector ${ }^{28}$.Although no significant association was found between the use of BHU and the performance of mammography in both age groups, when relating this variable to affiliation with a private health insurance in the group that had undergone mammography less than two years before the interview, most women who frequently used BHU did not have a private health insurance and, among those who never attended BHU, most had one. These results suggest the existence of two main ways of accessing the mammography in the municipality. For women who use primary care regularly, this exam is strongly influenced by the public health system, while for women who do not use primary care, the exam has a greater influence on supplementary health, that is, the private sector.

We also investigated women who did not perform mammography, stratified for two years to less than three years, three years or more, and those who never performed it. In the 40-49 and 50-69 age groups, $21 \%$ and $3.3 \%$ of participants had never been subjected to mammography, respectively. This important percentage of not performance of the exam in the younger age group is disquieting since a previous study reported that Brazilian women in the age group less than or equal to 40 years represented $17 \%$ of breast cancer cases with unfavorable clinicopathological characteristics ${ }^{29}$. On the other hand, the lowest percentage of failure to perform the exam among women aged 50-69 years suggests a strong impact of Brazilian public policies for breast cancer screening, which prioritize this age group.

A current discussion on screening for breast cancer by mammography is the definition of age for the exam. In Brazil, according to the Clinical Guidelines for the Control of Breast Cancer, the target age range of 50-69 years was established ${ }^{5,7,17}$. However, according to SBM, CBR, and Febrasgo, the recommendation of screening women with usual population risk involves annual mammography in the age group of 40-74 years ${ }^{12,15}$.
Brazilian clinical guidelines are similar to international recommendations such as those of the United States Preventive Services Task Force (USPSTF) ${ }^{30}$ and the Canadian Task Force on Preventive Health Care (CTFPHC) $)^{31}$. Per the USPSTF, biennial screening is indicated for women aged 50 to 74 years, and the decision to start screening mammography in women before 50 years must be individual ${ }^{30}$. In turn, the CTFPHC recommends screening for women aged 40-49 years as non-routine screening and, for women aged 50-69 years, as routine, that is, every 2-3 years ${ }^{31}$.

Previous scientific evidence points out that the balance between benefits and risks of mammographic screening is still more favorable in women aged 50-69 years without a family history of breast cancer ${ }^{32,33}$; however, there is evidence that mammographic screening in 40-49 years women significantly reduces the risk of breast cancer mortality ${ }^{34,35}$. Given this scenario, the age for mammographic screening in Brazil must be debated, because of the increasing incidence of breast cancer cases and the significant mortality rate $(26 \%)$ in women over 75 years ${ }^{12}$.

It is important to highlight that breast cancer screening depends a lot on primary care, as this is the level of health care at which the clinical breast exam is performed, as well as the request for mammography for the target population and the follow-up of the patient to evaluate results. Subsequently, the patient's approach involves the use of units of secondary complexity for mammography and other complementary exams, in addition to units of high complexity in the presence of a neoplasm. Therefore, it is essential to develop coordinated actions that cross the levels of strategies: from prevention, early detection, and timely treatment to palliative care ${ }^{36}$. However, inequalities in the distribution of resources and barriers in the flow of assistance in the health network when it comes to radiological exams can hinder a timely and accurate diagnosis, consequently increasing mortality and morbidity from breast cancer ${ }^{7,37,38}$.

As well as the socioeconomic aspects and the indicators of health service use, the uneven geographical distribution of mammography devices is also considered an important indicator of health inequality ${ }^{28}$. Previous studies point out that the inadequate distribution of this equipment contributes to the increasing inequality in access to services providing mammography ${ }^{22,27-29}$. According to Ramos et al., although there is a sufficient number of devices to cover the population, they are unevenly distributed across the country, which is accompanied by a reduced operational capacity ${ }^{28}$. In this context, the development of further studies that investigate the inequalities in the screening of breast cancer under the perspective of the spatial distribution of mammographs between different health districts of the city of Belo Horizonte would be suitable, since this information was not collected in the population survey.

This study has some limitations that must be taken into account. First, data were collected in-home interviews, so information about mammography screening was obtained 
by self-report. Thus, the memory bias to report when the last mammography exam was performed, and the information bias related to answers considered socially accepted may underestimate or overestimate our estimates. Second, the small sample size may have compromised the statistical power of the study to reveal significant associations. Finally, the study design prevents any conclusions about the chronology and causality of associations found. On the other hand, this study investigated several potential factors that could influence the performance of the mammography exam. Another strong point is that the "MOVE-SE Academias" Project included residents from all health districts of Belo Horizonte, thus representing the entire municipality. Thus, the sample consisted of participants with well-diversified characteristics in social, economic, and health terms.

\section{CONCLUSION}

The results showed that the proportion of mammography exams performed in a Brazilian urban center, even with a stable tendency compared to other studies, that is, without an increase over time, exceeded the goal recommended by the WHO in the age group of 50-69 years, despite the inequalities observed in screening for breast cancer for both sociodemographic characteristics and health service use. This finding is worrying, considering that mammography is an exam with great potential for early diagnosis. Thus, the analysis of inequalities in access to health services related to screening for breast cancer is an important element to be taken into account in the formulation of public policies aimed at promoting and preventing health problems for women.

\section{ACKNOWLEDGMENTS}

We would like to thank the Urban Health Observatory of Belo Horizonte (OSUBH) and all the researchers who contributed with this work; the Coordination for the Improvement of Higher Education Personnel (CAPES) for the postdoctoral scholarship from researcher Bruno de Souza Moreira; the National Council for Scientific and Technological Development (CNPq), for the partial financial support for the project (CNPq no. 552752/2011-8), and the research productivity scholarship from researcher Waleska Teixeira Caiaffa. In particular, to professors Deborah Carvalho Malta, from the Universidade Federal de Minas Gerais, and Pedro Rodrigues Curi Hallal, from the Universidade Federal de Pelotas, for their relevant participation in the process of financing with CNPq.

\section{AUTHORS' CONTRIBUTION}

A.S.M.: Conceptualization, investigation, methodology, formal analysis, validation, visualization, writing of original draft, and writing - review and editing.

B.S.M.: Conceptualization, investigation, methodology, validation, visualization, writing of original draft, and writing review and editing.

D.A.S.C.: Research, data curation, formal analysis, validation, visualization, and writing - review and editing.

A.C.S.A.: Conceptualization, investigation, methodology, data curation, formal analysis, supervision, validation, visualization, and writing - review and editing.

W.T.C.: Fundraising, project management, conceptualization, research, methodology, supervision, validation, visualization, and writing - review and editing.

\section{REFERENCES}

1. Akram M, Iqbal M, Daniyal M, Khan AU. Awareness and current knowledge of breast cancer. Biol Res. 2017;50(1):33. https://doi.org/10.1186/s40659-017-0140-9

2. Bray F, Ferlay J, Soerjomataram I, Siegel RL, Torre LA, Jemal A. Global cancer statistics 2018: GLOBOCAN estimates of incidence and mortality worldwide for 36 cancers in 185 countries. CA Cancer J Clin. 2018;68(6):394-424. https://doi. org/10.3322/caac. 21492

3. Instituto Nacional de Câncer José Alencar Gomes da Silva. Estimativa 2020: incidência de câncer no Brasil. Rio de Janeiro: INCA; 2019.

4. Brasil. Ministério da Saúde. DATASUS. Estatísticas Vitais. Sistema de Informações sobre Mortalidade - SIM [Internet]. Brasília: Ministério de Saúde; 2017 [Accessed on Feb 9, 2020]. Available at: http://tabnet.datasus.gov.br/cgi/tabcgi.exe?sim/ cnv/obt10uf.def
5. Instituto Nacional de Câncer José Alencar Gomes da Silva. Programa Nacional de Controle do Câncer de Mama. Rio de Janeiro: INCA; 2011.

6. Azevedo A, Ramos AL, Gonçalves V, Souza CF, Batista GS, Silva RBV, et al. O conhecimento de mulheres acerca do rastreamento do câncer de mama e suas implicações. Rev Med. 2019;98(3):187-93. https://doi.org/10.11606/issn.16799836.v98i3p187-193

7. Instituto Nacional de Câncer José Alencar Gomes da Silva. Diretrizes para a detecção precoce do câncer de mama no Brasil. Rio de Janeiro: INCA; 2015.

8. Buranello M, Meirelles MCCC, Walsh IAP, Pereira GA, Castro SS. Prática de exames de rastreio para câncer de mama e fatores associados - Inquérito de Saúde da Mulher em Uberaba MG, 2014. Ciên Saúde Colet. 2018;23(8):2661-70. http://dx.doi. org/10.1590/1413-81232018238.14762016 
9. Souza N, Falcão L, Nour G, Brito J, Castro M, Oliveira M. Breast cancer in young women: an epidemiological study in northeastern Brazil. Sanare. 2017;16(2):60-7.

10. Heywang-Köbrunner S, Hacker A, Sedlacek S. Breast care advantages and disadvantages of mammography screening. Breast Care. 2011;6(3):199-207. https://doi.org/10.1159/000329005

11. World Health Organization. Cancer control: knowledge into action: WHO guide for effective programmes. Module 3 Early Detection. WHO; 2007.

12. Urban L, Chala LF, Bauab SP, Schaefer M, Santos RP, Maranhão NMA, et al. Recomendações do Colégio Brasileiro de Radiologia e Diagnóstico por Imagem, da Sociedade Brasileira de Mastologia e da Federação Brasileira das Associações de Ginecologia e Obstetrícia para o rastreamento do câncer de mama. Radiol Bras. 2017;50(4):244-9. http://dx.doi.org/10.1590/0100-3984.2017-0069

13. Migowski A, Dias M, Nadanovsky P, Silva G, Sant’Ana D, Stein A. Diretrizes para detecção precoce do câncer de mama no Brasil. III - Desafios à implementação. Cad Saúde Pública. 2018;34(6):e00046317.http://dx.doi.org/10.1590/0102-311x00046317

14. Oliveira E, Pinheiro R, Melo E, Carvalho M. Condicionantes socioeconômicos e geográficos do acesso à mamografia no Brasil, 2003-2008. Ciên Saúde Colet. 2011;16(9):3649-64. http:// dx.doi.org/10.1590/S1413-81232011001000002

15. Schneider I, Giehl M, Boing A, D’Orsi E. Rastreamento mamográfico do câncer de mama no Sul do Brasil e fatores associados: estudo de base populacional. Cad Saúde Pública. 2014;30(9):1987-97.http://dx.doi.org/10.1590/0102-311X00162313

16. Lima-Costa MF, Matos DL. Prevalência e fatores associados à realização da mamografia na faixa etária de 50-69 anos: um estudo baseado na Pesquisa Nacional por Amostra de Domicílios (2003). Cad Saúde Pública. 2007;23(7):1665-73. http://dx.doi.org/10.1590/S0102-311X2007000700018

17. Silva G, Souza-Júnior P, Damacena G, Szwarcwald C. Detecção precoce do câncer de mama no Brasil: dados da Pesquisa Nacional de Saúde, 2013. Rev Saúde Pública. 2017;51(Supl. 1):19. https://doi.org/10.1590/S1518-8787.2017051000191

18. Lopes M, Caiaffa W, Andrade A, Malta D, Barber S, Friche A, et al. Disparities in food consumption between economically segregated urban neighbourhoods. Public Health Nutr. 2020;23(3):525-37. https://doi.org/10.1017/S1368980019003501

19. Fernandes A, Andrade A, Costa D, Dias M, Malta D, Caiaffa W. Programa Academias da Saúde e a promoção da atividade física na cidade: a experiência de Belo Horizonte, MG, Brasil. Ciên Saúde Colet. 2017;22(12):3903-14. http://dx.doi. org/10.1590/1413-812320172212.25282017

20. Fernandes A, Andrade A, Ramos C, Friche A, Dias M, Xavier $\mathrm{C}$, et al. Atividade física de lazer no território das Academias da Cidade, Belo Horizonte, Minas Gerais, Brasil: o efeito da presença de um programa de promoção da saúde na comunidade. Cad Saúde Pública. 2015;31(Supl. 1):1-13. http:// dx.doi.org/10.1590/0102-311X00104514

21. Brasil. Ministério da Saúde. Pesquisa Nacional de Saúde [Internet]. 2013 [Accessed on: Dec 14, 2019]. Available at: http:// tabnet.datasus.gov.br/cgi/deftohtm.exe?pns/pnskb.def

22. Melo E, Oliveira E, Chor D, Carvalho M, Pinheiro R. Inequalities in socioeconomic status and race and the odds of undergoing a mammogram in Brazil. Int J Equity Health. 2016;15:144. https://dx.doi.org/10.1186\%2Fs12939-016-0435-4
23. Relecom A, Arzel B, Perneger T. Effect of an organised screening program on socioeconomic inequalities in mammography practice, knowledge and attitudes. Int J Equity Health. 2018;17(1):95. https://doi.org/10.1186/s12939-018-0811-3

24. Ryerson A, Miller J, Eheman C, Leadbetter S, White M. Recent trends in U.S. mammography use from 2000-2006: a population-based analysis. Prev Med. 2008;47(5):477-82. https://doi.org/10.1016/j.ypmed.2008.06.010

25. Guyatt G, Rennie D, Meade MO, Cook DJ. Diretrizes para utilização da literatura médica: fundamentos para prática clínica da medicina baseada em evidências. $2^{\text {a }}$ ed. Porto Alegre: Artmed; 2011.

26. Barbosa Y, Oliveira A, Rabêlo P, Silva F, Santos A. Fatores associados à não realização de mamografia: Pesquisa Nacional de Saúde, 2013. Rev Bras Epidemiol. 2019;22:1-13. https://doi. org/10.1590/1980-549720190069

27. Theme Filha M, Leal M, Oliveira E, Esteves-Pereira A, Gama S. Regional and social inequalities in the performance of Pap test and screening mammography and their correlation with lifestyle: Brazilian national health survey, 2013. Int J Equity Health. 2016;15(1):1-8. https://doi.org/10.1186/s12939-016-0430-9

28. Ramos A, Alves L, Berra T, Popolin M, Arcoverde M, Campoy L, et al. Estratégia Saúde da Família, saúde suplementar e desigualdade no acesso à mamografia no Brasil. Rev Panam Salud Publica. 2018;42:1-9. https://doi.org/10.26633/ RPSP.2018.166

29. Franzoi MA, Rosa DD, Zaffaroni F, Werutsky G, Simon S, Bines J, et al. Advanced stage at diagnosis and worse clinicopathologic features in young women with breast cancer in Brazil: a subanalysis of the AMAZONA III study (GBECAM 0115). J Glob Oncol. 2019;5:1-10. https://doi.org/10.1200/jgo.19.00263

30. Siu AL. Screening for breast cancer: U.S. Preventive services task force recommendation statement. Ann Intern Med. 2016;164(4):279-96. https://doi.org/10.7326/M15-2886

31. Barbeau P, Stevens A, Beck A, Skidmore B, Arnaout A, Brackstone $\mathrm{M}$, et al. Breast cancer screening: protocol for an evidence report to inform an update of the Canadian Task Force on Preventive Health Care 2011 Guidelines. Ottawa Evidence Review Synthesis Centre; 2017.66 p.

32. Sardanelli F, Aase HS, Álvarez M, Azavedo E, Baarslag HJ, Balleyguier C, et al. Position paper on screening for breast cancer by the European Society of Breast Imaging (EUSOBI) and 30 national breast radiology bodies from Austria, Belgium, Bosnia and Herzegovina, Bulgaria, Croatia, Czech Republic, Denmark, Estonia, Finland, France, Germany, Greece, Hungary, Iceland, Ireland, Italy, Israel, Lithuania, Moldova, The Netherlands, Norway, Poland, Portugal, Romania, Serbia, Slovakia, Spain, Sweden, Switzerland and Turkey. Eur Radiol. 2017;27(7):2737-43. https://doi.org/10.1007/s00330-016-4612-z

33. Secretan BL, Scoccianti C, Loomis D, Benbrahim-Tallaa L, Bouvard V, Bianchini F, et al. Special Report Breast-Cancer Screening - Viewpoint of the IARC Working Group. N Engl J Med. 2015;372(24):2353-8. https://doi.org/10.1056/ nejmsr1504363

34. Moss SM, Wale C, Smith R, Evans A, Cuckle H, Duffy SW. Effect of mammographic screening from age 40 years on breast cancer mortality in the UK Age trial at 17 years' follow-up: A randomised controlled trial. Lancet Oncol. 2015;16(9):1123-32. https://doi.org/10.1016/S1470-2045(15)00128-X 
35. Hellquist BN, Duffy SW, Abdsaleh S, Björneld L, Bordás P, Tabár L, et al. Effectiveness of population-based service screening with mammography for women ages 40 to 49 years. Cancer. 2011;117(4):714-22. https://doi.org/10.1002/ cncr. 25650

36. Traldi M, Galvão P, Morais S, Fonseca M. Demora no diagnóstico de câncer de mama de mulheres atendidas no Sistema Público de Saúde. Cad Saúde Coletiva. 2016;24(2):18591. https://doi.org/10.1590/1414-462X201600020026
37. Thompson M, Lipson J, Daniel B, Harrigal C, Mullarkey P, Pal S, et al. Why are patients noncompliant with follow-up recommendations after MRI-guided core needle biopsy of suspicious breast lesions?. Am J Roentgenol. 2013;201(6):1391400. https://doi.org/10.2214/ajr.12.10282

38. Medlen K, Leahy N, Greene-Donnelly K, Fleishon H, Jiménez P. Better use of available radiology resources for women's health in Latin America and the Caribbean. Rev Panam Salud Publica. 2018;42:e115. https://doi.org/10.26633/rpsp.2018.115 